\title{
Extraskeletal osteochondroma on a cat's elbow
}

Authors:
Chantal Rosa ${ }^{1}$
Robert M. Kirberger ${ }^{1}$
Affiliations:
'Department of Companion
Animal Clinical Studies,
University of Pretoria,
South Africa
Correspondence to:
Chantal Rosa
Email:
chantal.rosa@up.ac.za
Postal address:
Private Bag X04,
Onderstepoort 0110,
South Africa
Dates:
Received: 08 Sept. 2011
Accepted: 16 Apr. 2012
Published: 10 Sept. 2012
How to cite this article:
Rosa, C. \& Kirberger,
osteochondroma on a
cat's elbow', Journal of the
South African Veterinary
Association $83(1)$, Art. \#104,
4 pages. http://dx.doi.
org/10.4102/jsava.v83i1.104

C 2012. The Authors. Licensee: AOSIS OpenJournals. This work is licensed under the Creative Commons Attribution License.
A solitary extraskeletal osteochondroma was diagnosed in a 6-year-old, castrated male Burmese cat, positive for feline leukaemia virus (FeLV). The cat presented with a rapidly growing, solid, non-painful mass on the craniolateral aspect of the left elbow. Radiographs revealed an oval, well circumscribed $2.0 \mathrm{~cm} \times 1.5 \mathrm{~cm} \times 1.5 \mathrm{~cm}$ mineralised mass separated from the underlying bone. Surgical excisional biopsy confirmed the diagnosis. Feline extraskeletal osteochondromas are benign tumours frequently seen in FeLV-positive cats which can transform into osteosarcomas or chondrosarcomas. Radiographically, they cannot be distinguished from a parosteal or an extraskeletal osteosarcoma.

\section{Introduction}

Feline skeletal osteochondromas account for $20 \%$ of primary benign bone tumours (Gradner et al. 2008) and they appear as sessile, bony masses with a trabecular pattern and smooth margins (Barr 2005; Dernell 2003; Dernell et al. 2005; Doige 1987; Gradner et al. 2008; Mahoney \& Lamb 1996; McAllister \& Tobin 2005; Pool \& Carrig 1972; Ranade \& Pacchiana 2011; Tan et al. 2010; Wood, Grant \& McKlveen 2002). They are classified according to the number of masses as solitary (solitary osteochondroma) or multiple (osteochondromatosis or multiple cartilaginous exostoses) and as skeletal (axial and appendicular) or extraskeletal, according to the location (Barr 2005; Dernell 2003; Dernell et al. 2005; Doige 1987; Gradner et al. 2008; Johnson \& Watson 2005; Levitin et al. 2003; Mahoney \& Lamb 1996; McAllister \& Tobin 2005; Pool \& Carrig 1972; Ranade \& Pacchiana 2011; Tan et al. 2010; Wood et al. 2002). There is also a synovial form that appears as multiple articular mineralised bodies that do not originate from the bone itself, being located within the joint or bursa (Barr 2005; Dernell 2003; Dernell et al. 2005; Doige 1987; Gradner et al. 2008; Johnson \& Watson 2005; Levitin et al. 2003; Mahoney \& Lamb 1996; McAllister \& Tobin 2005; Pool \& Carrig 1972; Ranade \& Pacchiana 2011; Tan et al. 2010; Wood et al. 2002).

Feline osteochondromas are rare entities and those that have been described previously have mainly been skeletal or synovial osteochondromas (Dernell 2003; Dernell et al. 2005; Doige 1987; Gradner et al. 2008; Levitin et al. 2003; Ranade \& Pacchiana 2011; Tan et al. 2010; Wood et al. 2002). Uncommonly, one feline extraskeletal osteochondroma has been reported as a case where several linear masses parallel to long bones with no osseous attachment were evident. (Levitin et al. 2003).

This communication describes the radiological findings of a second extraskeletal osteochondroma in a cat positive for feline leukaemia virus (FeLV) that presented with a solitary mineralised mass.

\section{Case history}

A 6-year-old castrated FeLV-positive male Burmese cat was presented to the Onderstepoort Veterinary Academic Hospital (OVAH) for a second opinion regarding a fast-growing solid mass on the craniolateral aspect of the left elbow. On clinical examination, the only abnormality detected was the presence of a hard, non-painful, immobile solid $2.0 \mathrm{~cm} \times 1.5 \mathrm{~cm} \times 1.5 \mathrm{~cm}$ mass on the craniolateral aspect of the left elbow that did not affect the orthopaedic or neurological function of the limb.

Abnormalities detected on haematology and serum biochemistry were the presence of Mycoplasma haemofelis and a mild to moderate increase of the alanine aminotransferase (ALT) and alkaline phosphatase (ALP), which could be attributed to this infection. The increased ALP could also have been associated with the bony mass. Urinalysis, faecal floatation and abdominal ultrasound were within normal limits.

\section{Radiographic findings and diagnosis}

Survey radiographs (craniocaudal and mediolateral views) of the left and right elbows, as well as metastatic thoracic views (ventrodorsal, right and left lateral recumbent views) were made. The thoracic and right elbow radiographs were normal. An additional non-conventional craniolateralcaudomedial oblique view of the left elbow was made to assess the relationship between the 
mass and the adjacent bones. The beam was adjusted to be tangential to the mass.

The radiographs revealed an oval, well-marginated, $2.0 \mathrm{~cm}$ $\times 1.5 \mathrm{~cm} \times 1.5 \mathrm{~cm}$ slightly irregular mineralised mass, with a trabecular pattern, cranio-lateral to the left elbow joint (Figure 1, Figure 2 and Figure 3). The mass was not attached to the underlying bones and had a mild associated soft tissue swelling (Figure 3). No osseous changes were present in the adjacent bones. Incidental flexor tendon origin dystrophic mineralisation (calcific tendinitis) was seen adjacent to the medial epicondyle (Figure 3). The radiographic findings were compatible with a juxta-articular mineralised mass. A parosteal osteosarcoma, extraskeletal osteosarcoma and an osteochondroma (solitary or synovial) were considered the main differential diagnoses. A less likely possibility was an extraskeletal chondrosarcoma.

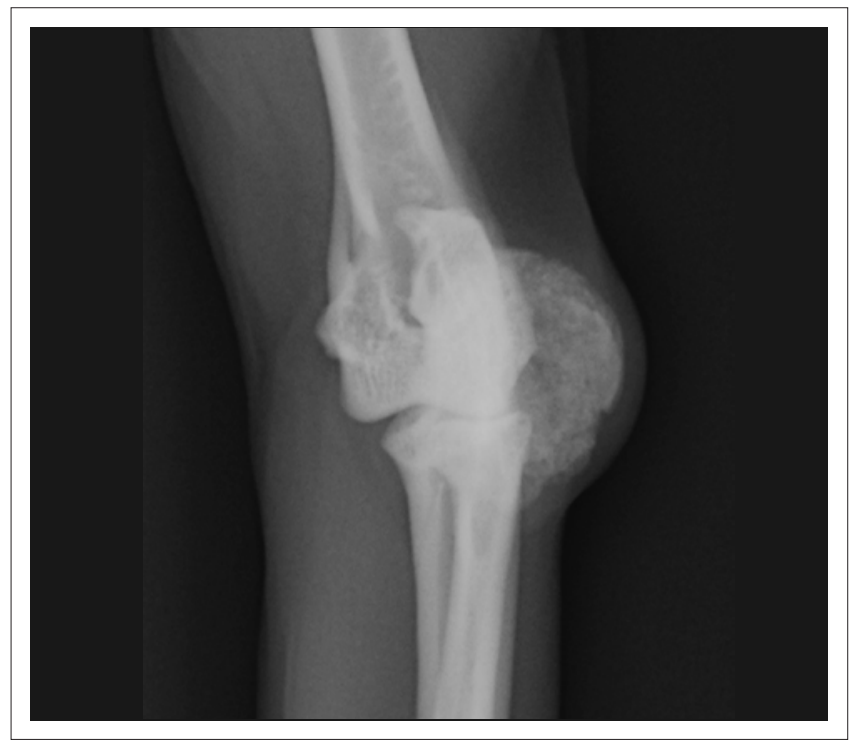

FIGURE 1: Craniocaudal view of the left elbow of a cat positive for feline leukaemia virus. Note the presence of an oval, well-circumscribed mineralised mass craniolateral to the elbow joint.

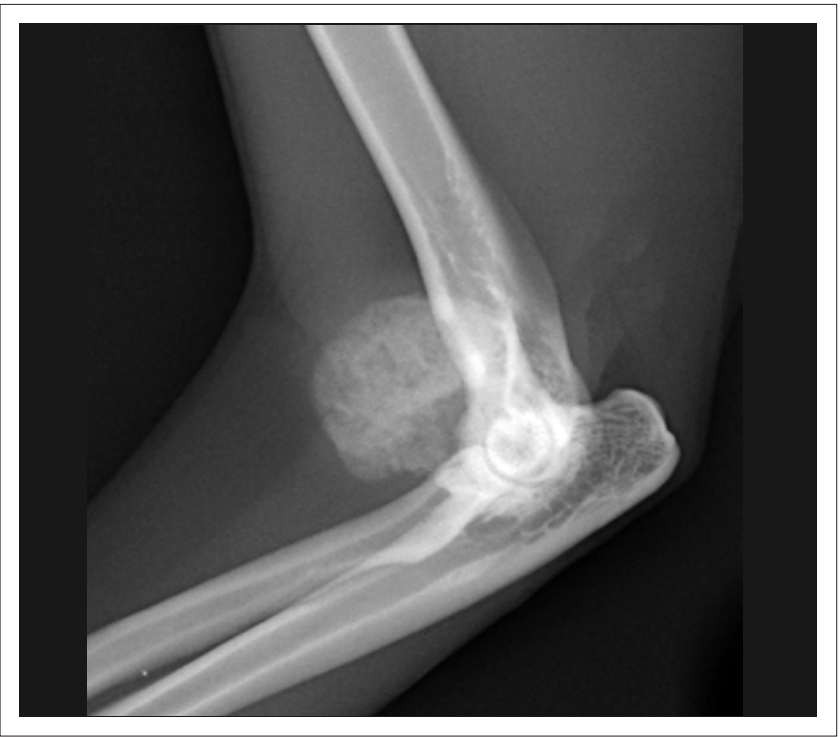

FIGURE 2: Mediolateral view of the left elbow of a cat positive for feline leukaemia virus. The mineralised, well-circumscribed mass is seen dorsolaterally to the left elbow joint.
An excisional surgical biopsy of the mass was performed and the histopathology confirmed the mass to be an osteochondroma. Postoperative radiographs confirmed its complete excision. Four months after surgery there was no radiographic evidence of re-growth. Yet, one month later, the cat presented with another $0.5 \mathrm{~cm} \times 0.3 \mathrm{~cm} \times 0.3 \mathrm{~cm}$ mass in the exact same location and with the same clinical and radiographic characteristics as the original osteochondroma (Figure 4). This second mass was surgically removed and histopathology confirmed it to be an osteochondroma. Four months after the second surgery the tumour showed no signs of recurrence.

\section{Ethical considerations}

This case report was written as a retrospective clinical case of a client-owned pet using data retrieved from the patient record system of the OVAH. The animal reported here was treated and housed according to the standard OVAH protocols for the management of client-owned pets. All diagnostic tests and treatments were performed as part of the routine work up and treatment of the patient. In other words, none of the tests and treatments were conducted for research purposes.

\section{Discussion}

Radiographically, a feline extraskeletal osteochondroma is indistinguishable from a parosteal osteosarcoma, extraskeletal osteosarcoma and an extraskeletal chondrosarcoma, so histopathology is required to confirm the diagnosis (Gradner et al. 2008; Tan et al. 2010). All can appear in the appendicular soft tissues as bony structures that do not invade the adjacent cortical bone (Gradner et al. 2008; Heldmann \& WagnerMann 2000; Tan et al. 2010).

Calcified structures associated with joints in the appendicular skeleton of dogs and cats can be normal anatomical structures or pathological processes (Mahoney \& Lamb 1996). Radiographically, these calcifications are classified according to their position in relation to the joint. They are considered articular if they are within the joint, periarticular if attached or peripheral to it and juxta-articular, as in this case, if close to the joint but not involved in it (Mahoney \& Lamb 1996). Diet, lifestyle, body condition, degenerative joint disease, FeLV status and neoplasia may play a role in the development of periarticular mineralised masses (Tan et al. 2010). A wide variety of conditions have been associated with these calcified bodies and guidelines to help in their interpretation have been published (Mahoney \& Lamb 1996).

Primary bone tumours are rare in cats, accounting for $4.9 \%$ of all the feline tumours (Dernell 2003; Dernell et al. 2005; Doige 1987; Durham, Popovitch \& Goldschmidt 2008). Of these, $67.0 \%-90.0 \%$ are malignant (Dernell 2003; Dernell et al. 2005; Doige 1987; Durham et al. 2008). Of the feline malignant skeletal tumours, osteosarcoma is the most common $(70.0 \%$ 80.0\%) (Dernell 2003; Dernell et al. 2005). Feline osteosarcomas can be classified as skeletal (medullary and parosteal) or extraskeletal (Dernell et al. 2005; Heldmann \& WagnerMann 2000). The feline parosteal osteosarcoma arises from the periosteal connective tissue of the axial or appendicular systems, grows slowly and, only in the late stage of the disease, invades the cortical bones (Heldmann \& Wagner- 
Mann 2000), making it a differential diagnosis in the early stages for any soft tissue mineralised mass. Feline extraskeletal osteosarcomas account for $40.0 \%$ of all feline osteosarcomas and they have been reported in the mammary gland, eye and in other locations (Dernell et al. 2005; Heldmann \& WagnerMann 2000). Another feline extraskeletal malignant tumour is chondrosarcoma, which is a rare soft tissue proliferation of malignant cells with chondroid differentiation (Romanucci et al. 2005). They have been reported more commonly in the extremities of cats but they can also occur extraskeletally (Durham et al. 2008; Johnson \& Watson 2005; Romanucci et al. 2005; Shaw et al. 2009). Owing to the limited number of cases, it is not certain whether extraskeletal chondrosarcomas are more or less aggressive than the skeletal forms, although it is thought that it depends on the type and success of the therapeutic intervention (Durham et al. 2008; Romanucci et al. 2005; Shaw et al. 2009).

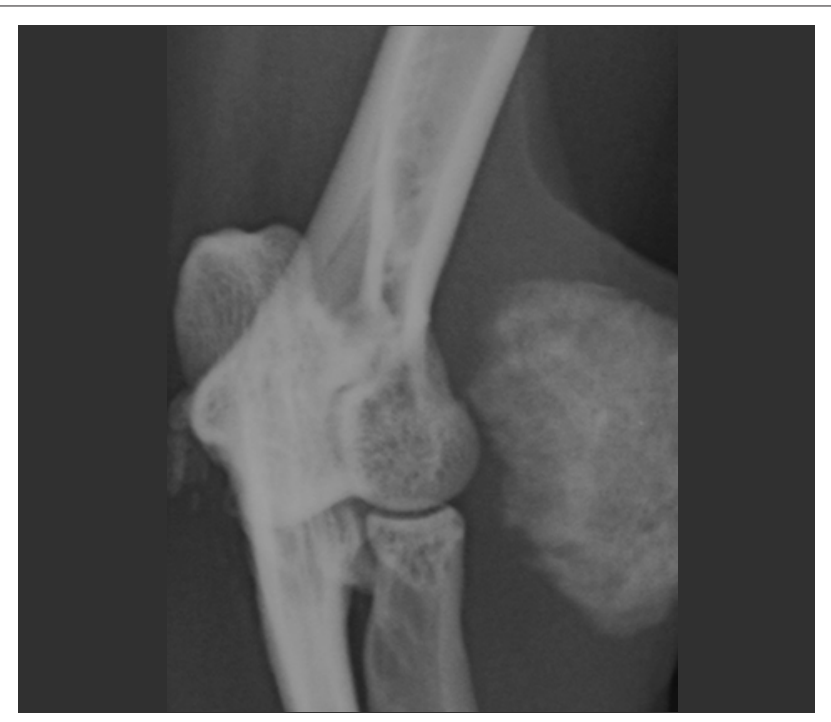

FIGURE 3: Craniolateral-caudomedial oblique view of the left elbow of a cat positive for feline leukaemia virus, clearly showing the mass as unattached to the bone. Calcification of the flexor tendon origin is also present and considered an incidental finding.

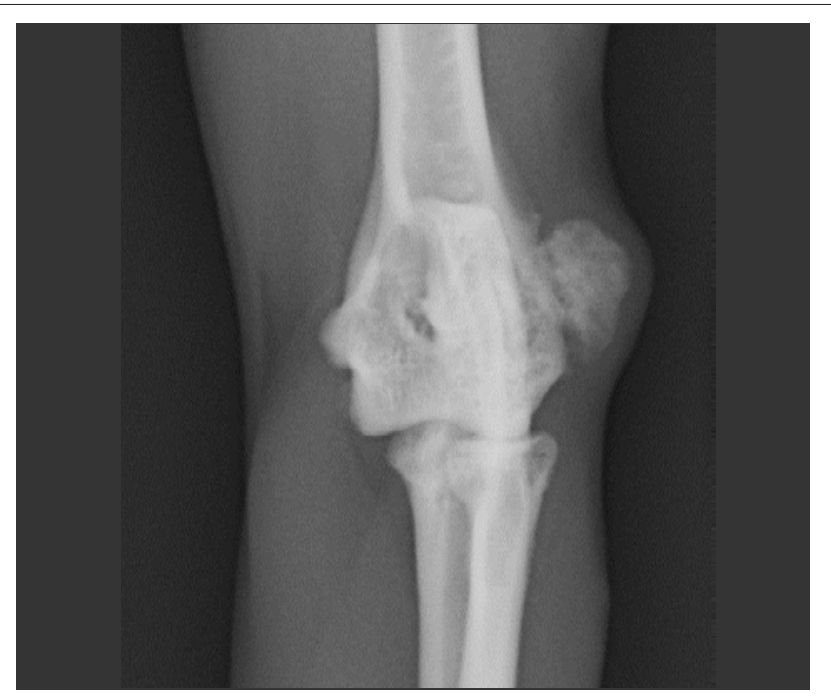

FIGURE 4: Craniocaudal view of the left elbow of a cat positive for feline leukaemia virus five months after initial presentation, showing local regrowth of the osteochondroma. Note the presence of the same radiographic characteristics as the initial osteochondroma.
In humans, osteochondromas are one of the most common benign bone tumours arising from bone (Malhotra et al. 2011). It is thought that they are caused by herniation of the growth plate and histologically they consist of a well-defined osseous mass with a trabecular pattern of bone formation and a cartilaginous hyaline cap (Malhotra et al. 2011). They are thought to be hereditary, having an autosomal dominant inherited form (Gunay et al. 2010). Soft tissue or extraskeletal osteochondromas are another form of osteochondroma in humans and they are thought to originate from the differentiation of mesenchymal cells of the soft tissues (Malhotra et al. 2011). Few cases have been reported arising in the hands, wrists, feet, knee, thigh, buttock and neck and they presented as gradually enlarging masses within the soft tissues that were painful if they impinged on adjacent structures (Malhotra et al. 2011). No cases have been reported of malignant transformation of human extraskeletal osteochondromas, possibly because they are excised before this transformation and marginal excision is curative (Malhotra et al. 2011).

In dogs, an extraskeletal osteochondroma has only been reported in the trachea (Cross, Tromblee \& Miller 2007). More commonly, they are skeletal osteochondromas located at sites of endochondral ossification (physeal origin) that stop growing after skeletal maturity (Barr 2005; Gunay et al. 2010; Johnson \& Watson 2005; McAllister \& Tobin 2005).

The main differences in osteochondromatosis between cats and dogs and humans are the growth pattern and the pathogenesis. In cats, they continue growing, whilst in dogs and humans the growth stops at physeal closure (Gradner et al. 2008; Levitin et al. 2003; Tan et al. 2010). The pathogenesis of feline osteochondroma is presumed to be related to FeLV infection of periosteal fibroblasts (Dernell 2003; Dernell et al. 2005; Gradner et al. 2008; Levitin et al. 2003; Ranade \& Pacchiana 2011; Tan et al. 2010; Wood et al. 2002). Viral particles morphologically similar to FeLV have been identified by electron microscopy in some cats, but immunodeficiency virus has not been implicated in this pathogenesis (Levitin et al. 2003). Approximately $20 \%$ of feline skeletal osteochondromas transform into osteosarcomas or chondrosarcomas (Gradner et al. 2008; Levitin et al. 2003; Ranade \& Pacchiana 2011; Wood et al. 2002).

Cats with osteochondromas can present with various clinical signs related to the location and stage of the disease, as well as secondary compression of the adjacent tissues. Skeletal osteochondromas tend to cause lameness, pain and paresis resulting from compression of the neurological structures (Johnson \& Watson 2005; Levitin et al. 2003; Ranade \& Pacchiana 2011). The extraskeletal linear osteochondroma previously described also presented with these signs (Levitin et al. 2003). In this case, the only clinical abnormality present was the external mass.

\section{Conclusion}

No effective treatment exists for feline osteochondromas because of the aetiology, but surgical excision with wide margins has been described as the treatment of choice in 
the case of osteochondromas (Gradner et al. 2008; Levitin et al. 2003; Tan et al. 2010). Surgery should be performed but local recurrence and new lesions are possible (Dernell 2003; Dernell et al. 2005; Doige 1987; Gradner et al. 2008; Ranade \& Pacchiana 2011; Tan et al. 2010; Wood et al. 2002), as in this case. Surgical removal is difficult because of the cartilaginous component tending to blend with the adjacent tissues, resulting in frequent recurrences of the lesions (Levitin et al. 2003), as in the re-growth of the initial osteochondroma in this case. Another factor playing a role in the recurrence of osteochondromatosis is the viral aetiology that does not allow a permanent cure (Levitin et al. 2003). Other cases of postoperative local recurrence, as in the case described here, and emergence of new lesions have been described previously (Johnson \& Watson 2005; Pool \& Carrig 1972).

More advanced imaging techniques, such as computed tomography or magnetic resonance imaging, can be useful to evaluate margins, characterise the lesion, plan surgery and assess the prognosis (Ranade \& Pacchiana 2011). Generally, however, the prognosis in cats is good to guarded depending on the progression of disease, its location, treatment options (Levitin et al. 2003) and recurrence. If this tumour is not surgically removed, there is a $20 \%$ chance of it transforming into a malignancy. If surgery is performed, the owners and veterinarians should be aware that this benign tumour may re-grow in the same location or in other sites because of its etiopathogenesis. We recommend the surgical removal of these benign tumours if possible, as well as further monitoring for recurrences in the same or other location or other locations.

\section{Acknowledgements}

The authors wish to thank Prof. M. Williams for his contributions to the histopathology analysis.

\section{Competing interests}

The authors declare that they have no financial or personal relationship(s) which may have inappropriately influenced them in writing this paper.

\section{Authors' contributions}

C.R. (University of Pretoria) was the main veterinary clinician responsible for this clinical case and wrote the case report. R.M.K. (University of Pretoria) gave intellectual and practical contributions regarding the radiographic study and writing description.

\section{References}

Barr, F., 2005, 'Long bones - Juvenile', in F. Barr \& R.M. Kirberger (eds.), BSAVA manua of canine and feline musculoskeletal imaging, pp. 19-31, BSAVA Publications, Gloucester.

Cross, J.R., Tromblee, T.C. \& Miller, J.M., 2007, 'Veterinary medicine today: What is your diagnosis?', Journal of the American Veterinary Medical Association 230 1807-1808. http://dx.doi.org/10.2460/javma.230.12.1807, PMid:17571979

Dernell, W.S., 2003, 'Tumours of the skeletal system', in J.M. Dobson \& B.D. Lascelles (eds.), BSAVA manual of canine and feline oncology, 2nd edn., pp. 179-195, BSAVA Publications, Gloucester.

Dernell, W.S., Ehrhart, N.P., Straw, R.C. \& Vail, D.M., 2005, 'Tumours of the skeletal system', in S.J. Withrow \& D.M. Vail (eds.), Withrow \& MacEwen's small animal clinical oncology, 4th edn., pp. 540-574, Elsevier Saunders, St Louis.

Doige, C.E., 1987, 'Multiple osteochondromas with evidence of malignant transformation in a cat', Veterinary Pathology 24, 457-459. PMid:3672812

Durham, A.C., Popovitch, C.A. \& Goldschmidt, M.H., 2008, 'Feline chondrosarcomas: A retrospective study of 67 cats (1987-2005)', Journal of the American Animal Hospital Association 44, 124-130. PMid:18451070

Gradner, G., Weissenbock, H., Kneissl, S., Benetka, V. \& Dupré, G., 2008, 'Use of latissimus dorsi and abdominal external oblique muscle for reconstruction of a thoracic wall defect in a cat with feline osteochondromatosis', Journal of Feline Medicine and Surgery 10, 88-94. http://dx.doi.org/10.1016/j.jfms.2007.06.005

Gunay, C., Atar, H., Yildiz, Y. \& Saglik, Y., 2010, 'Spinal osteochondroma: A report on six patients and a review of the literature', Archives of Orthopedic Trauma and Surgery 130, 1459-1465. http://dx.doi.org/10.1007/s00402-010-1058-7, PMid:20107821

Heldmann, E. \& Wagner-Mann, C., 2000, 'Feline osteosarcoma: 145 cases (19901995)', Journal of the American Animal Hospital Association 36, 518-521. 1995)', Journal

Johnson, K.A. \& Watson, A.D.J., 2005, 'Skeletal diseases', in S.J. Ettinger \& E.C. Feldman (eds.), Textbook of veterinary internal medicine, 6th edn., pp. 1965-1991, Elsevier Saunders, St Louis.

Levitin, B., Aroch, I., Aizenberg, I., Foreman, O. \& Shamir, M., 2003, 'Linear osteochondromatosis in a cat', Veterinary Radiology and Ultrasound 44, 660-664. http://dx.doi.org/10.1111/j.1740-8261.2003.tb00529.x

Mahoney, P.N. \& Lamb, C.R., 1996, 'Articular, periarticular and juxtaarticular calcified bodies in the dog and cat: A radiologic review', Veterinary Radiology and Ultrasound 37, 3-19. http://dx.doi.org/10.1111/j.1740-8261.1996.tb00806.x

Malhotra, K., Nunn, T., Chandramohan, M. \& Shanker, J., 2011, 'Metatarsal stress fractures secondary to soft-tissue osteochondroma in the foot: Case report and literature review', Foot and Ankle Surgery 17, e51-e54. http://dx.doi. org/10.1016/j.fas.2011.05.003, PMid:22017915

McAllister, H. \& Tobin, E., 2005, 'Long bones - Mature', in F. Barr \& R.M. Kirberger (eds.), BSAVA manual of canine and feline musculoskeletal imaging, pp. 32-48, BSAVA Publications, Gloucester.

Pool, R.R. \& Carrig, C.B., 1972, 'Multiple cartilaginous exostoses in a cat', Veterinary Pathology 9, 350-359.

Ranade, A. \& Pacchiana, P.D., 2011, 'Veterinary medicine today: What is your diagnosis?', Journal of the American Veterinary Medical Association 238, 12431244. http://dx.doi.org/10.2460/javma.238.10.1243, PMid:21568765

Romanucci, M., Bongiovanni, L., Petrizzi, L. \& Salda, L.D., 2005, 'Case report: Cutaneous extraskeletal mesenchymal chondrosarcoma in a cat', Veterinary Dermatology 16 , 121-124. http://dx.doi.org/10.1111/j.1365-3164.2005.00429.x, PMid:15842543

Shaw, S.C., Kent, M.S., Gordon, I.K., Collins, C.J., Greasby, T.A., Beckett, L.A. et al., 2009, 'Temporal changes in characteristics of injection-site sarcomas in cats: 392 cases (1990-2006)', Journal of the American Veterinary Medical Association 3, 376-380. http://dx.doi.org/10.2460/javma.234.3.376, PMid:19210260

Tan, C., Allan, G.S., Barfield, D., Krockenberger, M.B., Howlett, R. \& Malik, R., 2010 'Synovial osteochondroma involving the elbow of a cat', Journal of Feline Medicine and Surgery 12, 412-417. http://dx.doi.org/10.1016/j.jfms.2010.03.015

Wood, B.C., Grant, D.C. \& McKlveen, T.L., 2002, 'Veterinary medicine today: What is your diagnosis?', Journal of the American Veterinary Medical Association 221 939-940. http://dx.doi.org/10.2460/javma.2002.221.939, PMid:12369694 